\title{
Ayurvedic Medicine for the Treatment of Dementia: Mechanistic Aspects
}

\author{
Akhlaq A. Farooqui, ${ }^{1}$ Tahira Farooqui, ${ }^{1}$ Anil Madan, ${ }^{2}$ \\ Jolin Hwee-Jing Ong, ${ }^{3}$ and Wei-Yi Ong $\oplus^{3}$ \\ ${ }^{1}$ Department of Molecular and Cellular Biochemistry, The Ohio State University, Columbus, OH 43221, USA \\ ${ }^{2}$ Department of Pathology, Rajshree Medical Research Institute Bareilly, Bareilly, India \\ ${ }^{3}$ Department of Anatomy, National University of Singapore, Singapore 119260 \\ Correspondence should be addressed to Wei-Yi Ong; wei_yi_ong@nuhs.edu.sg
}

Received 19 December 2017; Revised 22 March 2018; Accepted 2 April 2018; Published 15 May 2018

Academic Editor: Ki-Wan Oh

Copyright (C) 2018 Akhlaq A. Farooqui et al. This is an open access article distributed under the Creative Commons Attribution License, which permits unrestricted use, distribution, and reproduction in any medium, provided the original work is properly cited.

\begin{abstract}
Ayurvedic medicine is a personalized system of traditional medicine native to India and the Indian subcontinent. It is based on a holistic view of treatment which promotes and supports equilibrium in different aspects of human life: the body, mind, and soul. Popular Ayurvedic medicinal plants and formulations that are used to slow down brain aging and enhance memory include Ashwagandha (Withania somnifera), Turmeric (Curcuma longa), Brahmi (Bacopa monnieri), Shankhpushpi (Convolvulus pluricaulis, Evolvulus alsinoides, and other species), gotu kola (Centella asiatica), and guggulu (Commiphora mukul and related species) and a formulation known as Brāhmī Ghrita, containing Brahmi, Vacā (Acorus calamus), Kustha (Saussurea lappa), Shankhpushpi, and Purāna Ghrita (old clarified butter/old ghee). The rationale for the utilization of Ayurvedic medicinal plants has depended mostly on traditional usage, with little scientific data on signal transduction processes, efficacy, and safety. However, in recent years, pharmacological and toxicological studies have begun to be published and receive attention from scientists for verification of their claimed pharmacological and therapeutic effects. The purpose of this review is to outline the molecular mechanisms, signal transduction processes, and sites of action of some Ayurvedic medicinal plants. It is hoped that this description can be further explored with modern scientific methods, to reveal new therapeutic leads and jump-start more studies on the use of Ayurvedic medicine for prevention and treatment of dementia.
\end{abstract}

\section{Introduction}

Due to an increase in life expectancy, it is estimated that the number of elderly people worldwide will increase to approximately 2.1 billion by the year $2050[1,2]$. Increase in age is a major risk factor for dementia, a clinical neurodegenerative syndrome characterized by impaired memory and activities of daily living, altered behavior, personality, and other cognitive dysfunctions [3] (Figure 1). Several types of dementia have been reported in human patients, including Alzheimer type of dementia (AD), vascular dementia, Lewy body dementia, and dementia as a result of diseases such as stroke, AIDS, and multiple sclerosis [4]. Among these,
$\mathrm{AD}$ is the most common cause of dementia and is characterized by progressive memory loss and other cognitive deficits, including impaired judgment and decision-making, and language disturbances. In contrast, vascular dementia is defined as loss of cognitive function resulting from ischemic, hypoperfusive, or hemorrhagic brain lesions [5, 6]. Major risk factors for dementia include old age, long-term consumption of "western" diet, physical and cognitive inactivity, and epigenetic and environmental factors [7]. Other risk factors for dementia include cardiovascular and cerebrovascular problems, excessive alcohol consumption, social isolation, traumatic brain injury, and having one or two copies of the $\mathrm{APOE} \epsilon 4$ genetic variant $[8,9]$. 


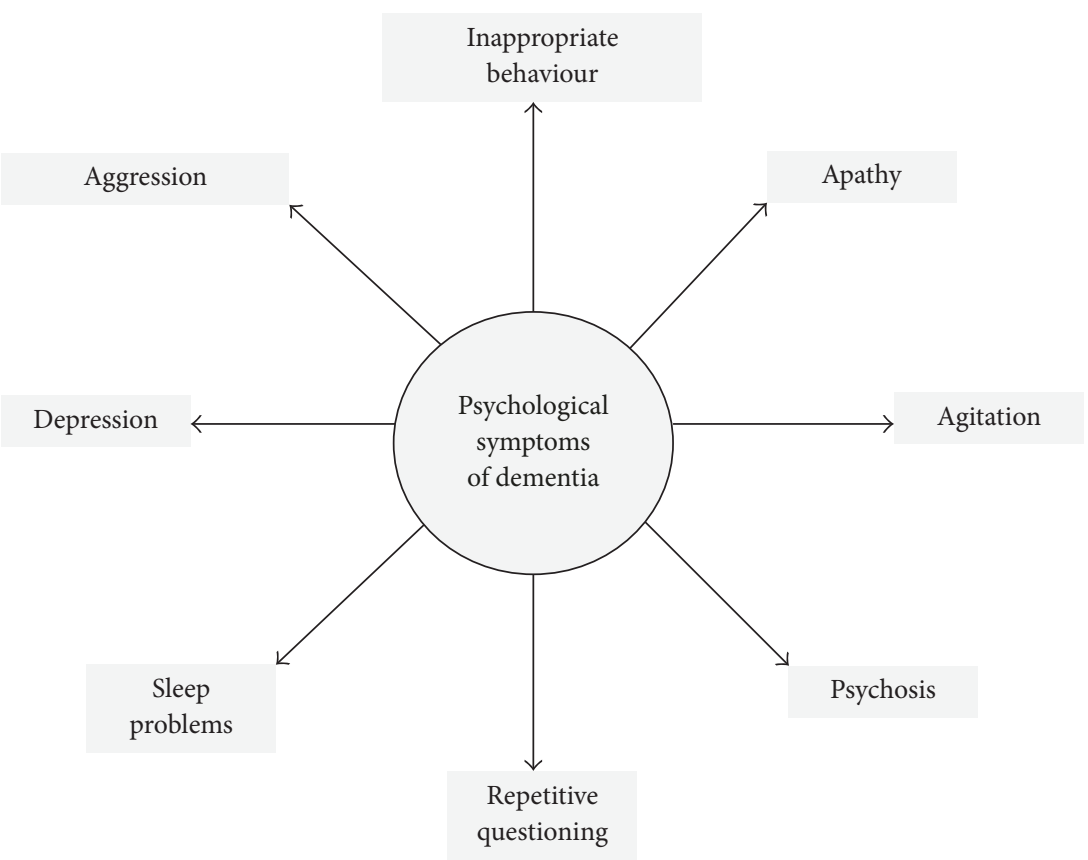

FIGURE 1: Symptoms of dementia.

Ayurvedic medicine is a personalized system of traditional medicine native to India and the Indian subcontinent. It is based on a holistic view of treatment which promotes and supports equilibrium in different aspects of human life: the body, mind, and soul [10]. Ayurveda dates back to the period of the Indus Valley civilization (about 3000 B.C.) and has been passed down through generations of oral tradition, like the other four knowledge texts (vedas) in ancient India. These include the Rigveda, Yajurveda, Samaveda, and Atharvaveda, which were composed between the 12 th and 7 th century B.C. Ayurvedic medicine includes descriptions of over 5000 signs and symptoms of various diseases and 700 herbs and 6,000 formulations to treat them. A direct reference to dementia in Ayurvedic literature has not been mentioned. However, the symptoms of forgetfulness and memory loss have been described [10]. Ayurvedic medicine mentions and explains the use of several herbs and their qualities for the treatment of nervous system disorders, including memory loss typically seen in older adults, but only recently have mechanistic studies been carried out, to determine the effects of these herbs on CNS disorders such as AD [11]. In recent years, there is renewed interest in the use of phytochemicals for the treatment of dementia, since pharmacological treatment of dementia using drugs (haloperidol, risperidone, aripiprazole, olanzapine, cholinesterase inhibitors, memantine, and benzodiazepines) is often inadequate and has many side effects [12-18]. The purpose of this review is to outline signal transduction processes and molecular mechanisms of some Ayurvedic medicinal plants used for the treatment of dementia. It is hoped that this description can be further explored with modern scientific validation approaches, to reveal new therapeutic leads and jump-start more studies on the use of Ayurvedic medicine for prevention and treatment of dementia.

\section{Ayurvedic Medicinal Plants for the Treatment of Dementia}

The use of complementary medicines, such as plant extracts, in dementia therapy varies according to different cultural traditions. Ayurvedic medicinal herbs modulate the neuroendocrine-immune systems and are also rich sources of antioxidants and anti-inflammatory compounds [19, 20]. They are claimed to enhance memory and rejuvenate cognitive functions [21-23]. Several Ayurvedic medicines have been exploited for the treatment and management of acute and chronic neurological diseases. Examples of popular Ayurvedic medications include Brāhmī Ghrita, Divya Medha Kwath, and Brento Forte. These formulations induce specific effects on brain functions, such as increase in blood flow and maintenance of memory [11].

2.1. Ashwagandha. Ashwagandha (Withania somnifera, fam. Solanaceae), or Indian Ginseng, is a common herb used in Ayurvedic medicine as an adaptogen or antistress agent. Ashwagandha root contains a large variety of compounds including 12 alkaloids, 40 withanolides, and several sitoindosides and flavonoids [24-26]. Withaferin A (WL-A) and withanolide A are two constituents which show similar pharmacokinetic profiles, except that the oral bioavailability for WL-A is 1.44 times greater than that of withanolide A [27] (Figure 2). These components produce antistress, antioxidant, and immunomodulatory effects in acute models of experimental stress [28-30]. According to Ayurvedic 

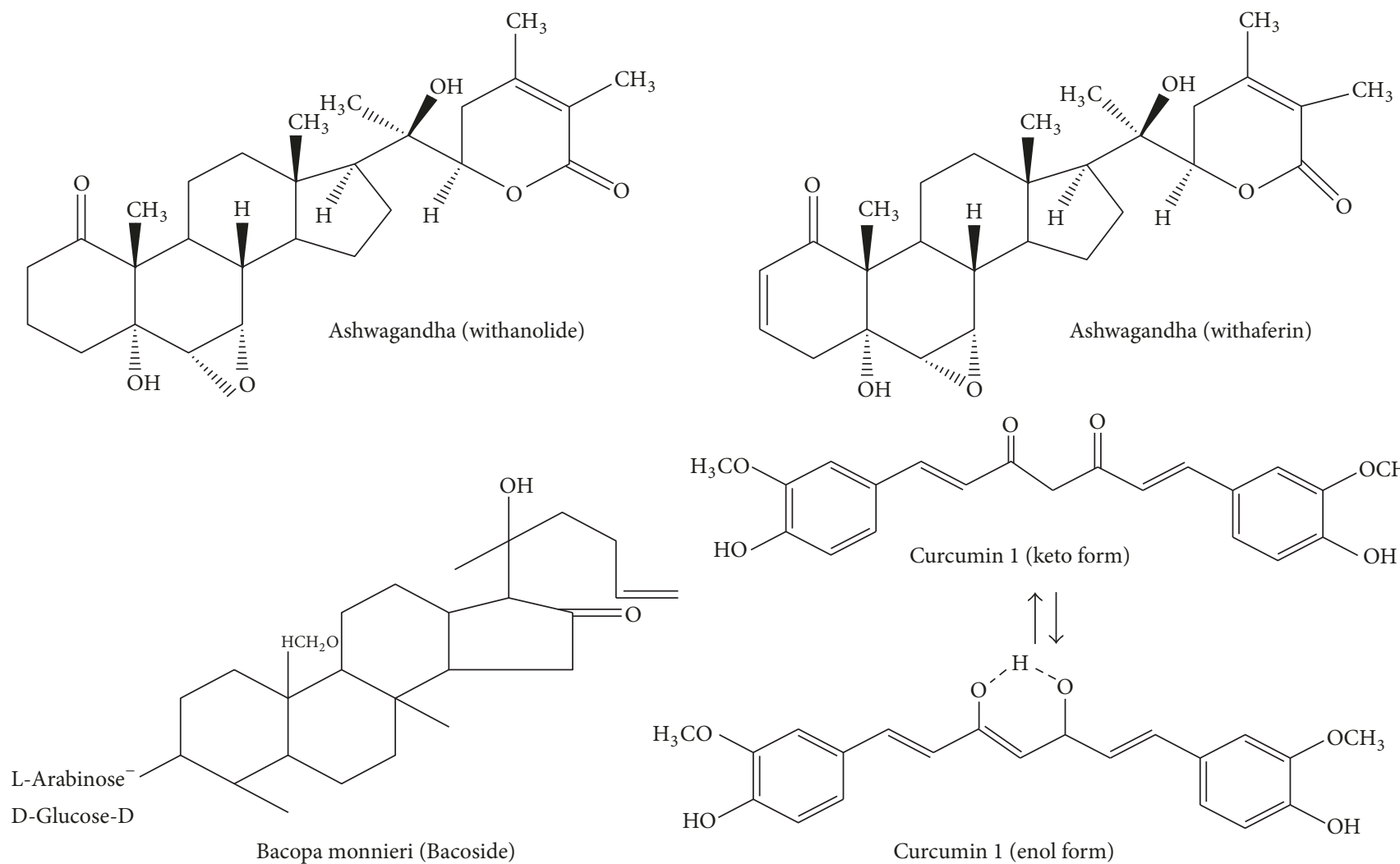<smiles>COc1cc(/C=C/C(=O)CC(=O)/C=C/c2ccc(O)c(OC)c2)ccc1O</smiles>

FIgURE 2: Chemical structures of withanolide, withaferin, bacoside, and curcumin.

medicine, Ashwagandha constituents provide a number of healthful effects such as youthful state of physical and mental health and increase in happiness. It is not only given to children as tonics but is consumed by the middle-aged and elderly to increase longevity [31, 32]. Recent studies have indicated that Ashwagandha root improves the body's defense against chronic diseases not only by improving cell-mediated immunity, but also through producing potent antioxidant and anti-inflammatory effects that protect against cellular damage caused by free radicals and inflammatory mediators [31, 32]. At the molecular level, Ashwagandha root may produce beneficial effects in $\mathrm{AD}$ by inhibiting the activation of NF- $\kappa \mathrm{B}$, blocking $\beta$-amyloid $(\mathrm{A} \beta)$ production, reducing apoptotic cell death, restoring synaptic function, and enhancing antioxidant effects through the migration of Nrf2 to the nucleus, where it increases the expression of antioxidant enzymes [33] (Figure 3). It is suggested that WL-A activates the translocation of Nrf2 to the nucleus, where the transcription factor upregulates the expression of neuroprotective proteins, such as heme oxygenase-1 [34, 35]. Treatment of human neuroblastoma SK-N-SH cells with methanolic extracts of Ashwagandha root results in dendrite extension, neurite outgrowth, and synapse formation [36, 37]. Moreover, treatment of cultured rat cortical neurons with $\mathrm{A} \beta(25-35)(10 \mu \mathrm{M})$ produces axonal and dendritic atrophy and pre- and postsynaptic loss, and these changes were abrogated by treatment with WL-A $(1 \mu \mathrm{M})$ [37]. WL-A also attenuates the expression of semaphorin $3 \mathrm{~A}$ to facilitate neural regeneration. The beneficial effects of Ashwagandha root constituents in neurodegenerative diseases may be due to their neurite promoting, antioxidant, anti-inflammatory, antiapoptotic, and anxiolytic activities, as well as their ability to improve mitochondrial dysfunction and restore energy levels and increase levels of antioxidant defenses such as reduced glutathione [38] (Figure 3).

In animals, WL-A (10 $\mu \mathrm{mol} \mathrm{kg}{ }^{-1} \mathrm{day}^{-1}$, for 13 days, p.o. $)$ restores $\mathrm{A} \beta$ (25-35)-induced memory deficit in mice and recovers the decline of axons, dendrites, and synapses in the cerebral cortex and hippocampus. Based on the above information, it is proposed that WL-A is an important candidate for the treatment of dementia and neurodegenerative diseases, since it is able to repair damaged neuronal networks $[33,38]$. Ashwagandha is a safe herb $[39,40]$, although a few people experience diarrhea or nausea after consuming the root. It should not be taken with barbiturate-type sedatives, since the herb can increase the effectiveness of these drugs. Ashwagandha can cross the blood-brain barrier and lower inflammation in the brain.

The half-lives of Ashwagandha in the circulation and the brain are not known. Large multicenter clinical trials of Ashwagandha in patients with dementia have not been performed. A preliminary study indicates that Withania somnifera (500 mg/day) added adjunctively to medications improves auditory-verbal working memory, reaction time, and social cognition in patients with bipolar disorders [41].

2.2. Turmeric. Curcumin $\left(\mathrm{C}_{21} \mathrm{H}_{20} \mathrm{O}_{6}\right)$ or diferuloylmethane (bis- $\alpha, \beta$-unsaturated $\beta$-diketone) (Figure 2 ) is a hydrophobic 


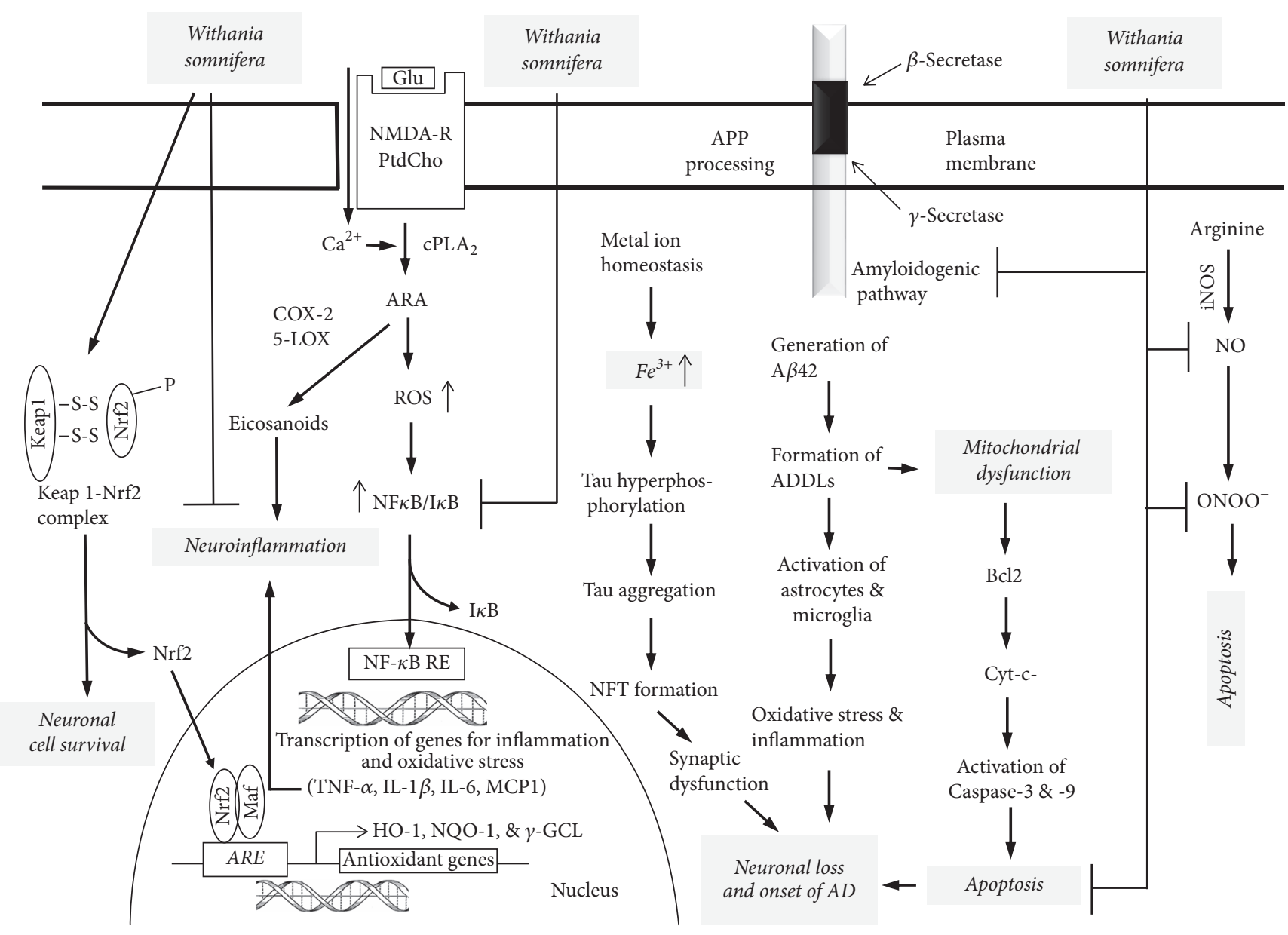

FIGURE 3: Hypothetical diagram showing target sites for the action of Ashwagandha (Withania somnifera). Glutamate (Glu); NMDA receptor (NMDA-R); phosphatidylcholine (PtdCho); cytosolic phospholipase $\mathrm{A}_{2}$ (cPLA $)$ ); cyclooxygenase-2 (COX-2); 5-lipoxygenase (5LOX); arachidonic acid (ARA); reactive oxygen species (ROS); nuclear factor- $\kappa \mathrm{B}(\mathrm{NF}-\kappa \mathrm{B})$; nuclear factor- $\kappa \mathrm{B}-$ response element (NF- $\kappa \mathrm{B}-\mathrm{RE})$; inhibitory subunit of NF- $\kappa \mathrm{B}$ (I- $\kappa \mathrm{B})$; tumor necrosis factor- $\alpha$ (TNF- $\alpha$ ); interleukin-1 $\beta$ (IL-1 $\beta$ ); interleukin-6 (IL-6); monocyte chemoattractant protein-1 (MCP-1); nuclear factor E2-related factor 2 (Nrf2); kelch-like ECH-associated protein 1 (Keap1); antioxidant response element (ARE); small leucine zipper proteins (Maf); heme oxygenase (HO-1); NADPH quinine oxidoreductase (NQO-1); $\gamma$-glutamate cystein ligase $(\gamma$-GCL); B-cell lymphoma 2 (Bcl-2); cytochrome (cyto-c); amyloid precursor protein (APP); $\beta$-amyloid (A $\beta$ ); A $\beta$-derived diffusible ligand (ADDL); and Alzheimer disease (AD).

polyphenolic compound (mol mass of 368.38) present in turmeric (an ingredient in curry powder). It is derived from the rhizome of Curcuma longa, which belongs to the family Zingiberaceae. It has antioxidant, anti-inflammatory, and cancer chemopreventive properties [42]. Curcumin reduces oxidative damage and improves cognitive functions related to the aging process. It induces antioxidant effects by modulating the Nrf2-keap1 pathway and reduces genomic instability events [43]. Nrf2 is primarily present in the cytoplasm, where it is bound with the Kelch-like ECH-associated protein 1 (Keap1). Interaction of curcumin with Keap 1 releases Nrf2, which migrates into the nucleus and binds as a heterodimer to antioxidant responsive elements in DNA, to initiate target gene expression. Nrf2-regulated genes include antioxidant enzymes, molecular chaperones, DNA repair enzymes, and anti-inflammatory response proteins [44] (Figure 4). These proteins promote the reduction in ROS generation while increasing the ability of the cell to repair any subsequent damage $[44,45]$. Curcumin also suppresses proinflammatory pathways by blocking the production of TNF- $\alpha$, IL- $1 \beta$, and other proinflammatory cytokines, including IL-8, MIP- $1 \beta$, and MCP-1, in astrocytes and microglia. Curcumin attenuates neuroinflammation through the inhibition of phospholipase $\mathrm{A}_{2}\left(\mathrm{PLA}_{2}\right)$ and cyclooxygenase (COX-2) enzymes associated with the metabolism of neural membrane phospholipids to prostaglandins (Figure 4). It reduces glial fibrillary acidic protein (GFAP) expression, improves spatial memory in the $\mathrm{A} \beta$-induced rat model of $\mathrm{AD}$, and decreases GFAP and COX-2 expression in A $\beta$-treated astrocytes [46]. Both in vitro and in vivo studies indicate that curcumin binds with $\mathrm{A} \beta$ and inhibits its aggregation [43, 47], as well as fibril and oligomer formation [43]. In vivo studies have shown that dietary curcumin not only crosses the blood-brain barrier and decreases $\mathrm{A} \beta$ deposition in $\mathrm{AD}$ transgenic mice [43], but also markedly inhibits Tau phosphorylation [48]. The absorption rate and bioavailability of curcumin can be 


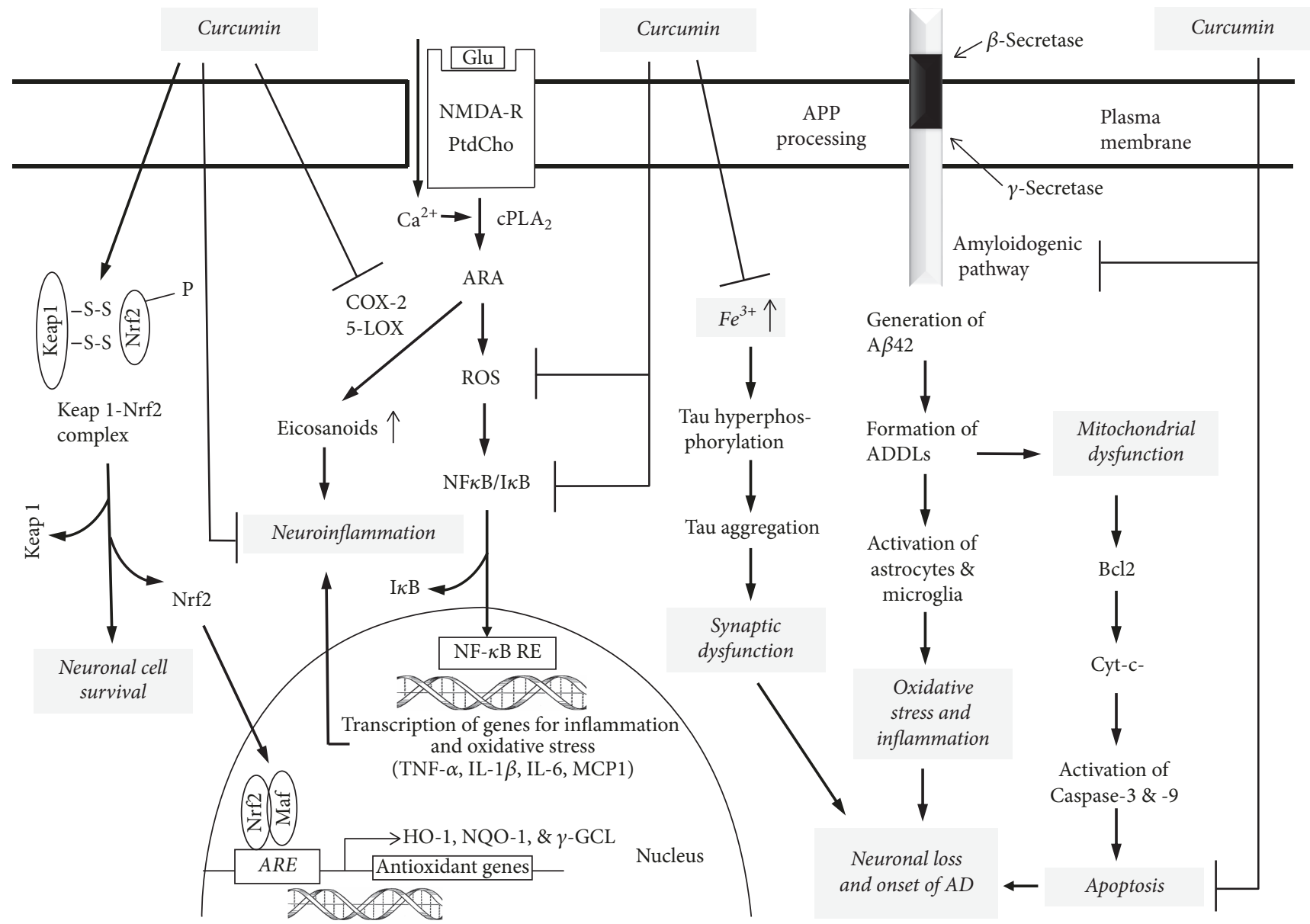

FIgURE 4: Hypothetical diagram showing target sites for the action of curcumin (diferuloylmethane) in signal transduction pathway. Glutamate (Glu); NMDA receptor (NMDA-R); phosphatidylcholine (PtdCho); cytosolic phospholipase $\mathrm{A}_{2}$ ( cPLA $_{2}$ ); cyclooxygenase-2 (COX2); 5-lipoxygenase (5-LOX); arachidonic acid (ARA); reactive oxygen species (ROS); nuclear factor- $\kappa \mathrm{B}$ (NF- $\kappa \mathrm{B}$ ); nuclear factor- $\kappa \mathrm{B}$-response element (NF- $\kappa \mathrm{B}-\mathrm{RE}$ ); inhibitory subunit of NF- $\kappa \mathrm{B}(\mathrm{I}-\kappa \mathrm{B})$; tumor necrosis factor- $\alpha$ (TNF- $\alpha$ ); interleukin-1 $\beta$ (IL-1 $\beta$ ); interleukin-6 (IL6); monocyte chemoattractant protein-1 (MCP-1); nuclear factor E2-related factor 2 (Nrf2); kelch-like ECH-associated protein 1 (Keap1); antioxidant response element (ARE); small leucine zipper proteins (Maf); heme oxygenase (HO-1); NADPH quinine oxidoreductase (NQO1); $\gamma$-glutamate cystein ligase ( $\gamma$-GCL); B-cell lymphoma 2 (Bcl-2); cytochrome (cyto-c); amyloid precursor protein (APP); $\beta$-amyloid (A $\beta)$; $\mathrm{A} \beta$-derived diffusible ligand (ADDL); and Alzheimer disease (AD).

increased by consuming it with black pepper (Piper nigrum). Studies have indicated that piperine, an active ingredient in black pepper, increases the bioavailability and bioefficacy of curcumin by inhibiting its glucuronidation [49]. Interestingly, consumption of piperine and curcumin has been found to protect against chronic unpredictable stress-induced cognitive impairment and oxidative damage in mice [50,51].

The half-lives of curcumin in the circulation and the brain are not known. Large multicenter clinical trials of curcumin in patients with dementia have not been performed, although a number of small studies have been conducted in healthy individuals. Curcumin $(400 \mathrm{mg} /$ day $)$ significantly improves performance on sustained attention and working memory tasks, compared with placebo, in healthy adults over 60 years of age [52]. Another study indicates that treatment with curcumin $(1500 \mathrm{mg} /$ day) results in no loss of cognition in the treatment group, whereas loss of cognition is found in the placebo group, among community-dwelling older adults [53].

2.3. Brahmi (Bacopa monnieri). Bacopa monnieri belongs to the family Scrophulariaceae and is found throughout the Indian subcontinent in wet, damp, and marshy areas [54]. It has many branches with small oblong leaves and purple flowers. This plant is not only used for the treatment of a number of nervous system disorders such as insomnia, anxiety, and epilepsy, but also used for enhancing memory and the intellect [55]. In Ayurvedic medicine, Bacopa monnieri is used as a memory enhancing, anti-inflammatory, analgesic, antipyretic, sedative, and antiepileptic agent, which acts as a nootropic (repairing damaged neurons and improving brain function). According to Ayurvedic medical practitioners, the memory enhancing properties of Bacopa monnieri are due to the presence of bacoside $\mathrm{A}$, assigned 


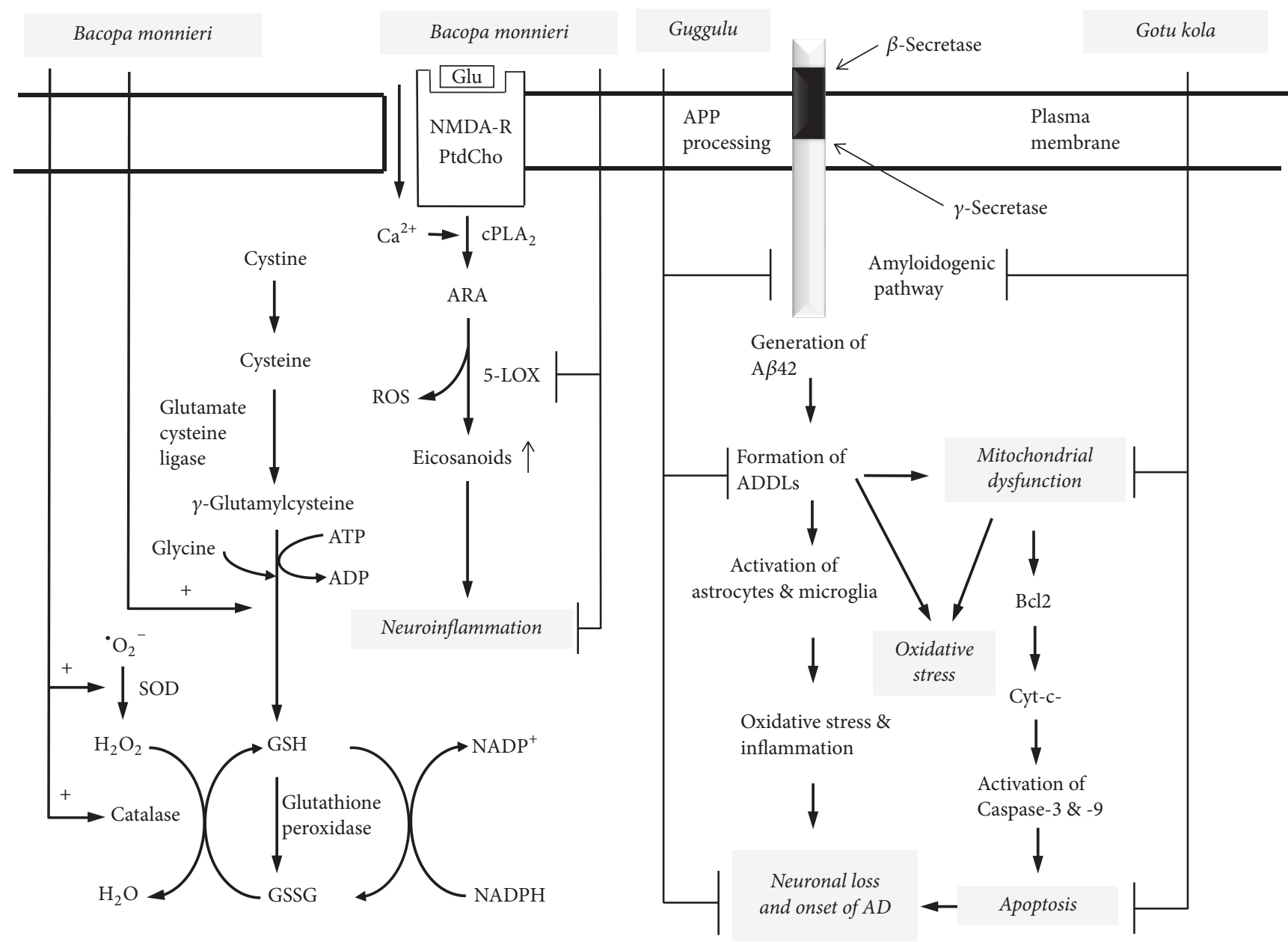

FIgure 5: Hypothetical diagram showing target sites for the action of Bacopa monnieri, guggulu, and gotu kola. Plasma membrane (PM); $\beta$-amyloid (A $\beta$ ); $\mathrm{A} \beta$-derived diffusible ligand (ADDL); B-cell lymphoma 2 (Bcl-2); cytochrome (cyto-c); amyloid precursor protein (APP); Alzheimer disease (AD); reduced glutathione (GSH); oxidized glutathione (GSSG).

as 3-(a-L-arabinopyranosyl)-O- $\beta$-D-glucopyranoside-10, 20dihydroxy-16-keto-dammar-24-ene [56], and bacoside B [57] (Figure 5).

Bacosides inhibit lipoxygenase activity and scavenge free radicals. They protect neural cells of the prefrontal cortex, hippocampus, and striatum against cytotoxicity and DNA damage implicated in $\mathrm{AD}$. Bacosides increase glutathione peroxidase, chelate iron $[58,59]$, and enhance nitric oxidemediated cerebral vasodilation, leading to improvements in total memory score [59]. Bacosides may also act by regulating membrane phosphorylation/dephosphorylation processes [60]. This leads to an increase in protein and RNA turnover in certain brain regions such as the hippocampus [57]. Furthermore, the combination of bacosides A and B not only induces antistress effects [61], but also protects the brain against smoking-induced membrane damage [62] and D-galactosamine-induced liver injury [63]. While there are no studies that prove that Bacopa monnieri causes side effects, it has been observed that excessive intake of Bacopa monnieri may lead to stomach upset, diarrhea, and nausea. The intake and use of Bacopa monnieri should be avoided by pregnant and breastfeeding women. To reduce the risk of side effects, it would be a good idea to gauge an individual's tolerance for this herb.

The half-lives of bacosides in the circulation and the brain are not known. A number of clinical trials have been carried out in human subjects on the use of Bacopa monnieri for improving cognition. Bacopa monnieri $(2 \times 150 \mathrm{mg})$ treatment for 90 days improves performance in a spatial working memory task in healthy humans $[64,65]$. Bacopa monnieri treatment for 3 months decreases the rate of forgetting of newly acquired information in human subjects between 40 and 65 years of age [55]. Standardized Bacopa monnieri extract treatment $(300 \mathrm{mg} /$ day $)$ for 12 weeks improves performance in a delayed recall and Stroop Task (assessing the ability to ignore irrelevant information), in participants without dementia aged 65 and above [66]. Moreover, treatment with Bacopa monnieri ( $300 \mathrm{mg} /$ day) improves verbal learning, memory acquisition, and delayed recall in healthy volunteers over 55 years of age [67].

Bacopa monnieri is used in a formulation known as Brāhmī Ghṛita, containing Brahmi (Bacopa monnieri), Vacā 
(Acorus calamus), Kuștha (Saussurea lappa), Shankhpushpi (Convolvulus pluricaulis), and Purāna Ghrita (old clarified butter/old ghee). The roots and rhizomes of Acorus calamus are used in Ayurvedic medicine on a regular basis for the treatment of insomnia, melancholia, neurosis, loss of memory, and remittent fevers. Convolvulus pluricaulis has been shown to improve learning and memory in rodents [68]. Saussurea lappa has been reported to produce antiinflammatory activity [69]. Old clarified butter or old ghee is described in Ayurveda as a memory enhancer, anticonvulsant, and anti-inflammatory agent [70, 71]. This formulation is used for the treatment of a number of neurological disorders such as anxiety and dementia [72]. The molecular mechanisms associated with the beneficial effects of Brāhmī Ghrita are not fully understood. However, it is reported that Brāhmī Ghrita may act not only by reversing cholinergic deficits in the frontal cortex and hippocampus [73], but also via alleviating cholinergic neurodegeneration [74], lowering norepinephrine, and increasing 5-hydroxytryptamine levels in the hippocampus, hypothalamus, and cerebral cortex [75]. The rhizome of Acorus calamus, another constituent of Brāhmī Ghrịta, is used as a brain tonic for improving memory and treatment of epilepsy. Methanolic extracts of Acorus calamus roots contain the essential oil $\beta$-asarone, which inhibits acetylcholinesterase [76]. Finally, old clarified butter is especially good for healing the mind [77]. The half-lives of Brāhmī Ghrita in the circulation and the brain are not known. Large multicenter clinical trials of Brāhmì Ghrita in patients with dementia have not been performed.

\subsection{Shankhpushpi. Shankhpushpi (Convolvulus pluricaulis)} is a common plant in India. It belongs to the family Convolvulaceae. The whole plant of Shankhpushpi is used in various formulae as a nervine tonic for improvement of memory and cognitive function $[78,79]$. Shankhpushpi is recommended for nervous system disorders, such as stress, anxiety, mental fatigue, and insomnia [79-81]. It has been suggested that Shankhpushpi has a calming effect by regulating the body's production of the stress hormones, adrenaline and cortisol [82]. The major bioactive components of Convolvulus pluricaulis are glycosides, flavonoids, coumarins, anthocyanins, and alkaloids. Sitosterol glycoside, octacosanol tetracosane, hydroxycinnamic acid, and glucose have also been isolated from the plant [83]. These metabolites contribute to its nootropic and memory enhancing properties, along with its other pharmacological activities [79, 82, 84]. Ethanolic extracts of Shankhpushpi improve learning and memory and induce antioxidant effects in rats [68]. Furthermore, ethanolic extracts of the whole Shankhpushpi plant, when administered to cholesterol-fed gerbils, induce reduction in serum levels of cholesterol, LDL cholesterol, triglycerides, and phospholipids [79]. The administration of ethanolic extracts of Shankhpushpi increases acetylcholine content in fields CA1 and CA3 of the hippocampus in a dose-dependent manner $[85,86]$. This is accompanied by a significant increase in the number of dendritic intersections, branch points, and dendritic processes arising from the cell bodies of neurons, in comparison with age-matched saline controls. Results suggest that ethanolic extracts of Shankhpushpi enhance memory by increasing neurite outgrowth $[86,87]$.

2.5. Gotu kola. Gotu kola (Centella asiatica) is another herb that is known as Brahmi (besides Bacopa monnieri). It belongs to the family Apiaceae and is a perennial creeping herb with long thick stems and smooth fan leaves. It is widely used as a blood purifier and for treating high blood pressure, enhancing memory, and promoting longevity. Tea made from gotu kola can be very helpful for relieving tension, relaxing the mind, and soothing anxiety. As a nervine adaptogen, constituents of gotu kola are capable of increasing intelligence, longevity, and memory. In the Ayurvedic system of medicine, water extracts of gotu kola are used not only for rejuvenating and restoring neural cells, but also for stimulating healthy sleep. It has a powerful effect on quality of life in disorders such as epilepsy. The primary active ingredients of gotu kola are saponins (also called triterpenoids), which include asiaticosides, in which a trisaccharide moiety is linked to the aglycone asiatic acid, madecassoside, and madasiatic acid [88]. Other components isolated from Centella asiatica such as brahmoside and brahminoside may be responsible for CNS and uterorelaxant actions but have yet to be confirmed by clinical studies. At the molecular level, asiaticoside derivatives from gotu kola (asiatic acid and asiaticoside) are capable of reducing hydrogen peroxide-induced cell death, decreasing free radical levels, and inhibiting $\mathrm{A} \beta$-mediated neural cell death in vitro. Results suggest a role for gotu kola in the prevention and treatment of $\mathrm{A} \beta$ toxicity and AD type of dementia (Figure 5) [89-91]. Gotu kola extracts possess antioxidant activity and can alter mitochondrial function [92, 93]. Because mitochondrial dysfunction is a common process that contributes to neurodegeneration in many neurodegenerative diseases [94], there are potentially broad implications for the use of water extracts of gotu kola.

In animals, water extracts of gotu kola attenuate cognitive impairment in the $\operatorname{Tg} 2576$ mouse model of $\mathrm{A} \beta$ accumulation without altering plaque burden [95] and can prevent $\mathrm{A} \beta$ toxicity in vitro [90]. Gotu kola has a safe record [96]. However, at high doses, it makes consumers drowsy. The half-lives of gotu kola in the circulation and the brain are not known. Large multicenter clinical trials of gotu kola in patients with dementia have not been performed. Studies on a few healthy human adults have shown promising cognitiveenhancing effects of gotu kola extracts [97, 98]. One study reports that treatment with Centella asiatica $(750 \mathrm{mg} /$ day) for 2 months enhances working memory and improvements in self-rated mood in healthy elderly volunteers [98].

2.6. Guggulu. Guggulu is an oleogum resin exuding from cracks and fissures or incisions in the bark of several plant species including Commiphora mukul, Commiphora molmol, Commiphora abyssinica, Commiphora Burseraceae, and Commiphora wightii. It is pale yellow or brown in color with an aromatic odor and bitter astringent taste [99]. Guggulu preparations contain $30 \%$ to $60 \%$ water-soluble gum, $20 \%$ to $40 \%$ alcohol-soluble resins, and about $8 \%$ volatile oils, which have many biological activities. Water-soluble extracts of guggulu contain mucilage, sugars, and proteins. Alcohol-soluble 
extracts of guggulu contain commiphoric acids, commiphorinic acid, and heerabomyrrhols. The volatile constituents of guggulu include terpenes, sesquiterpenoids, cuminic aldehyde, eugenol, the ketone steroids Z- and Eguggulsterone, and guggulsterols I, II, and III [100]. Guggulu contains ferulic acids, phenols, and other nonphenolic aromatic acids which are potent scavengers of superoxide radicals and can be important for the treatment of neurodegenerative diseases that are associated with oxidative stress [101, 102]. In addition, guggulsterones antagonize nuclear hormone receptors and decrease cholesterol levels, which may explain the hypolipidemic effects of guggulu extracts [103]. Many studies have indicated that there is a link between cholesterol, amyloid precursor protein processing, and $\mathrm{AD}[104,105]$. Cholesterol is an essential modulator of the physicochemical state and functional activity of the cell membrane and thus plays an essential role in the regulation of synaptic function and neuronal plasticity. In vitro and in vivo modulation of membrane cholesterol levels affect different cholesterol pools within the plasma membrane bilayer that are differentially sensitive to the disrupting effect of $\mathrm{A} \beta$ [106]. It is likely that beneficial effects of guggulu on $\mathrm{AD}$ may be due to its cholesterol-lowering effects [104]. Decreased neuronal cholesterol levels, in turn, inhibit the $\mathrm{A} \beta$-forming amyloidogenic pathway, possibly by removing amyloid precursor protein from cholesterol and sphingolipid-enriched membrane microdomains. These intriguing relationships raise hopes that cholesterol-lowering strategies may influence the progression of dementia associated with AD $[104,106]$. Administration of guggulipid (Z-guggulsterone) significantly lowers both serum LDL cholesterol and triglyceride levels, supporting the view that guggulipids may produce beneficial effects in the cardiovascular system [107].

In animals, Z-guggulsterone attenuates behavioral abnormalities induced by neuroinflammation in the forced swim and tail suspension tests [108] and prevents memory impairment in the scopolamine-induced memory impairment model, through activation of the CREB-BDNF signal [109]. Guggulipids also produce beneficial effects in the streptozotocin-induced memory deficit model of dementia, which can be attributed to their cholesterol-lowering, antioxidant, and antiacetylcholine esterase activities [107]. The half-lives of guggulu compounds in the circulation and the brain are not known. Large multicenter clinical trials of guggulu compounds in patients with dementia have not been performed.

\section{Conclusion}

Popular Ayurvedic medicinal plants (Ashwagandha, Turmeric, Brahmi, Shankhpushpi, gotu kola, and guggulu) not only reduce brain aging and induce antistress and memory enhancing effects which help in regeneration of neural tissues, but also induce antioxidant, anti-inflammatory, antiamyloidogenic, nutritional, and immune-supportive effects in the human body. Scientific validation and the documentation of Ayurvedic medicines are essential for their quality evaluation and global acceptance. Therapeutic efficacy of Ayurvedic herbal formulations might be enhanced, not only by achieving purity, but also through a better understanding of their biological effects. These days attempts are underway to achieve this goal. Once it is done, large multicenter clinical trials of Ayurvedic medicine can be planned and performed in patients with dementia and other neurodegenerative disorders.

\section{Conflicts of Interest}

The authors declare that there are no conflicts of interest regarding the publication of this paper.

\section{References}

[1] United Nations Department of Economic and Social Affairs Population Division, World Population Ageing 2015 (ST/ESA/ SER.A/390), United Nations, New York, NY, USA, 2015.

[2] WHO, "Dementia," http://www.who.int/mediacentre/factsheets/ fs362/en/.

[3] A. L. Sosa-Ortiz, I. Acosta-Castillo, and M. J. Prince, "Epidemiology of Dementias and Alzheimer's Disease," Archives of Medical Research, vol. 43, no. 8, pp. 600-608, 2012.

[4] K. Ritchie and S. Lovestone, "The dementias," The Lancet, vol. 360, no. 9347, pp. 1759-1766, 2002.

[5] G. C. Román, "Vascular dementia: distinguishing characteristics, treatment, and prevention," Journal of the American Geriatrics Society, vol. 51, no. 5, supplement 2, pp. S296-S304, 2003.

[6] P. Moorhouse and K. Rockwood, "Vascular cognitive impairment: current concepts and clinical developments," The Lancet Neurology, vol. 7, no. 3, pp. 246-255, 2008.

[7] A. A. Farooqui, Neurochemical aspects of Alzheimer's disease : risk factors, pathogenesis, biomarkers, and potential treatment strategies, Academic Press, Amsterdam, Netherlands, 2017.

[8] J. A. Sonnen, E. B. Larson, S. Haneuse et al., "Neuropathology in the adult changes in thought study: A review," Journal of Alzheimer's Disease, vol. 18, no. 3, pp. 703-711, 2009.

[9] A. Qaseem, V. Snow, J. T. Cross Jr. et al., "Current pharmacologic treatment of dementia: A clinical practice guideline from the American college of physicians and the American academy of family physicians," Annals of Internal Medicine, vol. 148, no. 5, pp. 370-378, 2008.

[10] S. Mishra, B. Trikamji, S. Singh, P. Singh, and R. Nair, "Historical perspective of Indian neurology," Annals of Indian Academy of Neurology, vol. 16, no. 4, pp. 467-477, 2013.

[11] B. V. Manyam, "Dementia in Ayurveda," The Journal of Alternative and Complementary Medicine, vol. 5, no. 1, pp. 81-88, 1999.

[12] K. M. Sink, K. F. Holden, and K. Yaffe, "Pharmacological treatment of neuropsychiatric symptoms of dementia: A review of the evidence," Journal of the American Medical Association, vol. 293, no. 5, pp. 596-608, 2005.

[13] E. Lonergan, J. Luxenberg, and J. Colford, "Haloperidol for agitation in dementia," The Cochrane Database of Systematic Reviews, vol. 2, article no. CD002852, Article ID D002852, 2002.

[14] C. Ballard and R. Howard, "Neuroleptic drugs in dementia: benefits and harm," Nature Reviews Neuroscience, vol. 7, no. 6, pp. 492-500, 2006.

[15] K. Tifratene, V. Manera, R. Fabre et al., "Antipsychotic prescribing for Alzheimer's disease and related disorders in specialized settings from 2010 to 2014 in France: A repeated cross-sectional study," Alzheimer's Research \& Therapy, vol. 9, no. 1, article no. 34, 2017. 
[16] R. McShane, A. Areosa Sastre, and N. Minakaran, "Memantine for dementia," The Cochrane Database of Systematic Reviews, vol. 2, article no. CD003154, Article ID D003154, 2006.

[17] D. B. Hogan, P. Bailey, S. Black et al., "Diagnosis and treatment of dementia: 5. Nonpharmacologic and pharmacologic therapy for mild to moderate dementia," Canadian Medical Association Journal, vol. 179, no. 10, pp. 1019-1026, 2008.

[18] C. Peisah, D. K. Y. Chan, R. Mckay, S. E. Kurrle, and S. G. Reutens, "Practical guidelines for the acute emergency sedation of the severely agitated older patient," Internal Medicine Journal, vol. 41, no. 9, pp. 651-657, 2011.

[19] S. K. Brahma and P. K. Debnath, "Therapeutic importance of Rasayana drugs with special reference to their multi-dimensional actions," Aryavaidyan, vol. 16, pp. 160-163, 2003.

[20] N. N. Rege, U. M. Thatte, and S. A. Dahanukar, "Adaptogenic properties of six rasayana herbs used in ayurvedic medicine," Phytotherapy Research, vol. 13, no. 4, pp. 275-291, 1999.

[21] L. Schlebusch, B. A. Bosch, G. Polglase, I. Kleinschmidt, B. J. Pillay, and M. H. Cassimjee, "A double-blind, placebo-controlled, double-centre study of the effects of an oral multivitaminmineral combination on stress," South African Medical Journal, vol. 90 , no. 12, pp. 1216-1223, 2000.

[22] B. M. Murphy and L. C. Frigo, "Development, implementation, and results of a successful multidisciplinary adverse drug reaction reporting program in a university teaching hospital," Hospital Pharmacy Journal, vol. 28, no. 12, pp. 1199-1204, 1993.

[23] R. Govindarajan, M. Vijayakumar, and P. Pushpangadan, "Antioxidant approach to disease management and the role of "Rasayana" herbs of Ayurveda," Journal of Ethnopharmacology, vol. 99, no. 2, pp. 165-178, 2005.

[24] L. Mishra, B. B. Singh, and S. Dagenais, "Scientific basis for the therapeutic use of Withania somnifera (ashwagandha): a review," Alternative Medicine Review, vol. 5, no. 4, pp. 334-346, 2000.

[25] N. J. Dar, A. Hamid, and M. Ahmad, "Pharmacologic overview of Withania somnifera, the Indian Ginseng," Cellular and Molecular Life Sciences, vol. 72, no. 23, pp. 4445-4460, 2015.

[26] M. H. Mirjalili, E. Moyano, M. Bonfill, R. M. Cusido, and J. Palazón, "Steroidal lactones from Withania somnifera, an ancient plant for novel medicine," Molecules, vol. 14, no. 7, pp. 2373-2393, 2009.

[27] D. Patil, M. Gautam, S. Mishra et al., "Determination of withaferin A and withanolide A in mice plasma using highperformance liquid chromatography-tandem mass spectrometry: application to pharmacokinetics after oral administration of Withania somnifera aqueous extract," Journal of Pharmaceutical and Biomedical Analysis, vol. 80, pp. 203-212, 2013.

[28] S. K. Bhattacharya, R. K. Goel, R. Kaur, and S. Ghosal, "Anti-stress activity of sitoindosides VII and VIII, new acylsterylglucosides from Withania somnifera," Phytotherapy Research, vol. 1, no. 1, pp. 32-37, 1987.

[29] R. Agarwal, S. Diwanay, P. Patki, and B. Patwardhan, "Studies on immunomodulatory activity of Withania somnifera (Ashwagandha) extracts in experimental immune inflammation," Journal of Ethnopharmacology, vol. 67, no. 1, pp. 27-35, 1999.

[30] J. H. Oh, T.-J. Lee, J.-W. Park, and T. K. Kwon, "Withaferin A inhibits iNOS expression and nitric oxide production by Akt inactivation and down-regulating LPS-induced activity of NF$\kappa$ B in RAW 264.7 cells," European Journal of Pharmacology, vol. 599, no. 1-3, pp. 11-17, 2008.

[31] S. S. Abbas and N. Singh, Anti-stress Agents (Herbs) of Indian Origin - Herbal Drugs, A twenty-first century perspective, D. R.
A. D. O. Delhi, Ed., Institute of Nuclear Medicine and Allied, New Delhi, India, 2006.

[32] M. R. Ven Murthy, P. K. Ranjekar, C. Ramassamy, and M. Deshpande, "Scientific basis for the use of Indian ayurvedic medicinal plants in the treatment of neurodegenerative disorders: 1. Ashwagandha," Central Nervous System Agents in Medicinal Chemistry, vol. 10, no. 3, pp. 238-246, 2010.

[33] R. Sandhir and A. Sood, "europrotective Potential of Withania somnifera (Ashwagandha) in Neurological Conditions," in Science of Ashwagandha: Preventive and Therapeutic Potentials, S. Kaul and R. Wadhwa, Eds., pp. 373-387, Springer International Publishing, Cham, Germany, 2017.

[34] M. Narayan, K. W. Seeley, and U. K. Jinwal, "Identification and quantitative analysis of cellular proteins affected by treatment with withaferin a using a SILAC-based proteomics approach," Journal of Ethnopharmacology, vol. 175, pp. 86-92, 2015.

[35] G. Y. Sun, R. Li, J. Cui et al., "Withania somnifera and Its Withanolides Attenuate Oxidative and Inflammatory Responses and Up-Regulate Antioxidant Responses in BV-2 Microglial Cells," NeuroMolecular Medicine, vol. 18, no. 3, pp. 241-252, 2016.

[36] C. Tohda, T. Kuboyama, and K. Komatsu, "Dendrite extension by methanol extract of Ashwagandha (roots of Withania somnifera) in SK-N-SH cells," NeuroReport, vol. 11, no. 9, pp. 1981$1985,2000$.

[37] T. Kuboyama, C. Tohda, and K. Komatsu, "Neuritic regeneration and synaptic reconstruction induced by withanolide A," British Journal of Pharmacology, vol. 144, no. 7, pp. 961-971, 2005.

[38] N. Singh, M. Bhalla, P. de Jager, and M. Gilca, "An overview on Ashwagandha: A Rasayana (Rejuvenator) of Ayurveda," African Journal of Traditional, Complementary and Alternative Medicines, vol. 8, no. 5, pp. 208-213, 2011.

[39] D. Choudhary, S. Bhattacharyya, and S. Bose, "Efficacy and Safety of Ashwagandha (Withania somnifera (L.) Dunal) Root Extract in Improving Memory and Cognitive Functions," Journal of Dietary Supplements, vol. 14, no. 6, pp. 599-612, 2017.

[40] T. Kuboyama, C. Tohda, and K. Komatsu, "Effects of Ashwagandha (Roots of Withania somnifera) on neurodegenerative diseases," Biological \& Pharmaceutical Bulletin, vol. 37, no. 6, pp. 892-897, 2014.

[41] K. N. R. Chengappa, C. R. Bowie, P. J. Schlicht, D. Fleet, J. S. Brar, and R. Jindal, "Randomized placebo-controlled adjunctive study of an extract of Withania somnifera for cognitive dysfunction in bipolar disorder," Journal of Clinical Psychiatry, vol. 74, no. 11, pp. 1076-1083, 2013.

[42] A. Goel, A. B. Kunnumakkara, and B. B. Aggarwal, "Curcumin as "Curecumin": from kitchen to clinic," Biochemical Pharmacology, vol. 75, no. 4, pp. 787-809, 2008.

[43] F. Yang, G. P. Lim, A. N. Begum et al., "Curcumin inhibits formation of amyloid $\beta$ oligomers and fibrils, binds plaques, and reduces amyloid in vivo," The Journal of Biological Chemistry, vol. 280, no. 7, pp. 5892-5901, 2005.

[44] H. K. Bryan, A. Olayanju, C. E. Goldring, and B. K. Park, "The Nrf2 cell defence pathway: Keap1-dependent and -independent mechanisms of regulation," Biochemical Pharmacology, vol. 85, no. 6, pp. 705-717, 2013.

[45] S. C. Gupta, S. Prasad, J. H. Kim et al., "Multitargeting by curcumin as revealed by molecular interaction studies," Natural Product Reports, vol. 28, no. 12, pp. 1937-1955, 2011.

[46] Y. Wang, H. Yin, L. Wang et al., "Curcumin as a potential treatment for Alzheimer's disease: a study of the effects of curcumin on hippocampal expression of glial fibrillary acidic 
protein," American Journal of Chinese Medicine, vol. 41, no. 1, pp. 59-70, 2013.

[47] H.-S. Hong, S. Rana, L. Barrigan et al., "Inhibition of Alzheimer's amyloid toxicity with a tricyclic pyrone molecule in vitro and in vivo," Journal of Neurochemistry, vol. 108, no. 4, pp. 1097-1108, 2009.

[48] Q.-L. Ma, F. Yang, E. R. Rosario et al., "Beta-amyloid oligomers induce phosphorylation of tau and inactivation of insulin receptor substrate via c-Jun $\mathrm{N}$-terminal kinase signaling: suppression by omega- 3 fatty acids and curcumin," The Journal of Neuroscience, vol. 29, no. 28, pp. 9078-9089, 2009.

[49] G. Shoba, D. Joy, T. Joseph, M. Majeed, R. Rajendran, and P. S. S. R. Srinivas, "Influence of piperine on the pharmacokinetics of curcumin in animals and human volunteers," Planta Medica, vol. 64, no. 4, pp. 353-356, 1998.

[50] P. Rinwa and A. Kumar, "Piperine potentiates the protective effects of curcumin against chronic unpredictable stressinduced cognitive impairment and oxidative damage in mice," Brain Research, vol. 1488, pp. 38-50, 2012.

[51] A. Sehgal, M. Kumar, M. Jain, and D. K. Dhawan, "Piperine as an adjuvant increases the efficacy of curcumin in mitigating benzo(a)pyrene toxicity," Human \& Experimental Toxicology, vol. 31, no. 5, pp. 473-482, 2012.

[52] K. H. M. Cox, A. Pipingas, and A. B. Scholey, "Investigation of the effects of solid lipid curcumin on cognition and mood in a healthy older population," Journal of Psychopharmacology, vol. 29, no. 5, pp. 642-651, 2015.

[53] S. R. Rainey-Smith, B. M. Brown, H. R. Sohrabi et al., "Curcumin and cognition: A randomised, placebo-controlled, doubleblind study of community-dwelling older adults," British Journal of Nutrition, vol. 115, no. 12, pp. 2106-2113, 2016.

[54] G. V. Satyavati, M. K. Raina, and M. Sharma, Medicinal Plants of India, Indian Council of Medical Research, New Delhi, India, 1976.

[55] S. Roodenrys, D. Booth, S. Bulzomi, A. Phipps, C. Micallef, and J. Smoker, "Chronic effects of Brahmi (Bacopa monnieri) on human memory," Neuropsychopharmacology, vol. 27, no. 2, pp. 279-281, 2002.

[56] N. Chatterji, R. Rastogi, and M. L. Dhar, Chemical examination of Bacopa monniera Wettst.: Part I-Isolation of chemical constituents,.

[57] H. K. Singh and B. N. Dhawan, "Drugs affecting learning and memory," Lectures in neurobiology, vol. 1, pp. 189-207, 1992.

[58] P. Anand, H. B. Nair, B. Sung et al., "Erratum: Design of curcumin-loaded PLGA nanoparticles formulation with enhanced cellular uptake, and increased bioactivity in vitro and superior bioavailability in vivo (Biochem. Pharmacol. 79 (2010) (330-338) DOI: 10.1016/j.bcp.2009.09.003)," Biochemical Pharmacology, vol. 102, p. 143, 2016.

[59] K. S. Chaudhari, N. R. Tiwari, R. R. Tiwari, and R. S. Sharma, "Neurocognitive effect of nootropic drug Brahmi (Bacopa monnieri) in Alzheimer's disease," Annals of Neurosciences, vol. 24, no. 2, pp. 111-122, 2017.

[60] H. K. Singh, R. C. Srimal, A. K. Srivastava, N. K. Garg, and B. N. Dhawan, "Neuropsychopharmacological effects of bacosides A and B," in in Proceedings of Fourth Conference on the Neurobiology of Learning and Memory, vol. 20, pp. 17-20, Irvine, CA, USA, 1990.

[61] D. Kar Chowdhuri, D. Parmar, P. Kakkar, R. Shukla, P. K. Seth, and R. C. Srimal, "Antistress effects of bacosides of Bacopa monnieri: modulation of Hsp70 expression, superoxide dismutase and cytochrome P450 activity in rat brain," Phytotherapy Research, vol. 16, no. 7, pp. 639-645, 2002.
[62] S. Ramakrishnan and T. Sumathi, "Hepatoprotective activity of Bacopa monniera on D-galactosamine induced hepatotoxicity in rats," Natural Product Sciences, vol. 13, no. 3, pp. 195-198, 2007.

[63] T. Sumathi and A. Nongbri, "Hepatoprotective effect of Bacoside-A, a major constituent of Bacopa monniera Linn," Phytomedicine, vol. 15, no. 10, pp. 901-905, 2008.

[64] C. Stough, J. Lloyd, J. Clarke et al., "The chronic effects of an extract of Bacopa monniera (Brahmi) on cognitive function in healthy human subjects," Psychopharmacology, vol. 156, no. 4, pp. 481-484, 2001.

[65] C. Stough, L. A. Downey, J. Lloyd et al., "Examining the nootropic effects of a special extract of Bacopa monniera on human cognitive functioning: 90 day double-blind placebocontrolled randomized trial," Phytotherapy Research, vol. 22, no. 12, pp. 1629-1634, 2008.

[66] C. Calabrese, W. L. Gregory, M. Leo, D. Kraemer, K. Bone, and B. Oken, "Effects of a standardized Bacopa monnieri extract on cognitive performance, anxiety, and depression in the elderly: a randomized, double-blind, placebo-controlled trial," The Journal of Alternative and Complementary Medicine, vol. 14, no. 6, pp. 707-713, 2008.

[67] A. Morgan and J. Stevens, "Does bacopa monnieri improve memory performance in older persons? Results of a randomized, placebo-controlled, double-blind trial," The Journal of Alternative and Complementary Medicine, vol. 16, no. 7, pp. 753759, 2010.

[68] A. Nahata, U. K. Patil, and V. K. Dixit, "Effect of Convulvulus pluricaulis Choisy. On learning behaviour and memory enhancement activity in rodents," Natural Product Research (Formerly Natural Product Letters), vol. 22, no. 16, pp. 1472-1482, 2008.

[69] J. Y. Cho, K. U. Baik, J. H. Jung, and M. H. Park, "In vitro antiinflammatory effects of cynaropicrin, a sesquiterpene lactone, from Saussurea lappa," European Journal of Pharmacology, vol. 398, no. 3, pp. 399-407, 2000.

[70] K. D. Yadav and K. R. Reddy, "Standardization of Brahmi Ghrita with special reference to its pharmaceutical study," International Journal of Ayurvedic Medicine, vol. 3, pp. 16-21, 2012.

[71] K. D. Yadav, K. R. Reddy, and V. Kumar, "Beneficial effect of Brahmi Ghrita on learning and memory in normal rat," An International Quarterly Journal of Research in Ayurveda, vol. 35, no. 3, pp. 325-329, 2014.

[72] B. Dhawan and H. Singh, "Pharmacological studies on bacopa monniera, an Ayurvedic nootropic agent," European Neuropsychopharmacology, vol. 6, p. 144, 1996.

[73] A. Russo and F. Borrelli, "Bacopa monniera, a reputed nootropic plant: an overview," Phytomedicine, vol. 12, no. 4, pp. 305-317, 2005.

[74] S. J. Sara, "Noradrenergic-cholinergic interaction: its possible role in memory dysfunction associated with senile dementia," Archives of Gerontology and Geriatrics, vol. 1, pp. 99-108, 1989.

[75] M. K. Saraf, S. Prabhakar, and A. Anand, "Neuroprotective effect of Bacopa monniera on ischemia induced brain injury," Pharmacology Biochemistry \& Behavior, vol. 97, no. 2, pp. 192197, 2010.

[76] M. H. Oh, P. J. Houghton, W. K. Whang, and J. H. Cho, "Screening of Korean herbal medicines used to improve cognitive function for anti-cholinesterase activity," Phytomedicine, vol. 11, no. 6, pp. 544-548, 2004.

[77] R. Chandre, K. N. Murthy, and R. H. Singh, "Evaluation of the efficacy of kushmandaghrta in the management of depressive illness," Aryavaidyan, vol. 18, pp. 87-90, 2004. 
[78] S. W. Bihaqi, M. Sharma, A. P. Singh, and M. Tiwari, "Neuroprotective role of Convolvulus pluricaulis on aluminium induced neurotoxicity in rat brain," Journal of Ethnopharmacology, vol. 124, no. 3, pp. 409-415, 2009.

[79] J. Malik, M. Karan, and K. Vasisht, "Nootropic, anxiolytic and CNS-depressant studies on different plant sources of shankhpushpi," Pharmaceutical Biology, vol. 49, no. 12, pp. 1234-1242, 2011.

[80] V. Kumar, "Potential medicinal plants for CNS disorders: an overview," Phytotherapy Research, vol. 20, no. 12, pp. 1023-1035, 2006.

[81] R. H. Singh, K. Narsimhamurthy, and G. Singh, "Neuronutrient impact of Ayurvedic Rasayana therapy in brain aging," Biogerontology, vol. 9, no. 6, pp. 369-374, 2008.

[82] N. K. Sethiya, A. Nahata, S. H. Mishra, and V. K. Dixit, "An update on Shankhpushpi, a cognition-boosting Ayurvedic medicine," Journal of Chinese Integrative Medicine, vol. 7, no. 11, pp. 1001-1022, 2009.

[83] V. Jatwa, P. Khirwadkar, and K. Dashora, "Indian traditional memory enhancing herbs and their medicinal benefits," Indian Journal of Research in Pharmacy and Biotechnology, vol. 2, no. 1, p. 1030, 2014.

[84] P. K. Mukherjee, V. Kumar, N. S. Kumar, and M. Heinrich, "The Ayurvedic medicine Clitoria ternatea-From traditional use to scientific assessment," Journal of Ethnopharmacology, vol. 120, no. 3, pp. 291-301, 2008.

[85] K. Sharma, M. Bhatnagar, and S. K. Kulkarni, "Effect of Convolvulus pluricaulis Choisy. and Asparagus racemosus willd on learning and memory in young and old mice: A comparative evaluation," Indian Journal of Experimental Biology (IJEB), vol. 48, no. 5, pp. 479-485, 2010.

[86] K. Rai, K. D. Murthy, K. S. Karanth, K. Nalini, M. S. Rao, and K. K. Srinivasan, "Clitoria ternatea root extract enhances acetylcholine content in rat hippocampus," Fitoterapia, vol. 73, no. 7-8, pp. 685-689, 2002.

[87] K. S. Rai, K. D. Murthy, K. S. Karanth, and M. S. Rao, “Clitoria ternatea (Linn) root extract treatment during growth spurt period enhances learning and memory in rats," Indian Journal of Physiology and Pharmacology, vol. 45, no. 3, pp. 305-313, 2001.

[88] B. Singh and R. P. Rastogi, "A reinvestigation of the triterpenes of Centella asiatica," Phytochemistry, vol. 8, no. 5, pp. 917-921, 1969.

[89] M. Dhanasekaran, L. A. Holcomb, A. R. Hitt et al., "Centella asiatica extract selectively decreases amyloid $\beta$ levels in hippocampus of Alzheimer's disease animal model," Phytotherapy Research, vol. 23, no. 1, pp. 14-19, 2009.

[90] N. Gray, J. Morré, J. Kelley et al., "Centella asiatica Protects Against the Toxic Effects of Intracellular beta-amyloid Accumulation," Planta Medica, vol. 79, no. 10, 2013.

[91] N. E. Gray, H. Sampath, J. A. Zweig, J. F. Quinn, and A. Soumyanath, "Centella asiatica Attenuates Amyloid- $\beta$-Induced Oxidative Stress and Mitochondrial Dysfunction," Journal of Alzheimer's Disease, vol. 45, no. 3, pp. 933-946, 2015.

[92] A. Prakash and A. Kumar, "Mitoprotective effect of Centella asiatica against aluminum-induced neurotoxicity in rats: Possible relevance to its anti-oxidant and anti-apoptosis mechanism," Neurological Sciences, vol. 34, no. 8, pp. 1403-1409, 2013.

[93] G. K. Shinomol and Muralidhara, "Prophylactic neuroprotective property of Centella asiatica against 3-nitropropionic acid induced oxidative stress and mitochondrial dysfunctions in brain regions of prepubertal mice," NeuroToxicology, vol. 29, no. 6, pp. 948-957, 2008.
[94] A. A. Farooqui, "Neurochemical aspects of neurotraumatic and neurodegenerative diseases," Neurochemical Aspects of Neurotraumatic and Neurodegenerative Diseases, pp. 1-401, 2010.

[95] A. Soumyanath, Y.-P. Zhong, E. Henson et al., "Centella asiatica extract improves behavioral deficits in a mouse model of Alzheimer's disease: Investigation of a possible mechanism of action," International Journal of Alzheimer's Disease, Article ID 381974, 2012.

[96] P. O. Deshpande, V. Mohan, and P. Thakurdesai, "Preclinical safety assessment of standardized extract of Centella asiatica (L.) urban leaves," Toxicology International, vol. 22, no. 1, pp. 1020, 2015.

[97] R. D. O. Dev, "Comparison on cognitive effects of Centella asiatica in healthy middle age female and male volunteers," Annals of Nutrition and Metabolism, vol. 55, p. 709, 2009.

[98] J. Wattanathorn, L. Mator, S. Muchimapura et al., "Positive modulation of cognition and mood in the healthy elderly volunteer following the administration of Centella asiatica," Journal of Ethnopharmacology, vol. 116, no. 2, pp. 325-332, 2008.

[99] P. Sarup, S. Bala, and S. Kamboj, " Pharmacology and Phytochemistry of Oleo-Gum Resin of ," Scientifica, vol. 2015, pp. 1-14, 2015.

[100] C. Ulbricht, E. Basch, P. Szapary et al., "Guggul for hyperlipidemia: A review by the Natural Standard Research Collaboration," Complementary Therapies in Medicine, vol. 13, no. 4, pp. 279-290, 2005.

[101] M. Perluigi, G. Joshi, R. Sultana et al., "In vivo protective effects of ferulic acid ethyl ester against amyloid-beta peptide 1-42induced oxidative stress," Journal of Neuroscience Research, vol. 84, no. 2, pp. 418-426, 2006.

[102] R. Sultana, A. Ravagna, H. Mohmmad-Abdul, V. Calabrese, and D. A. Butterfield, "Ferulic acid ethyl ester protects neurons against amyloid $\beta$-peptide(1-42)-induced oxidative stress and neurotoxicity: relationship to antioxidant activity," Journal of Neurochemistry, vol. 92, no. 4, pp. 749-758, 2005.

[103] L. A. Nohr, L. B. Rasmussen, and J. Straand, "Resin from the mukul myrrh tree, guggul, can it be used for treating hypercholesterolemia? A randomized, controlled study," Complementary Therapies in Medicine, vol. 17, no. 1, pp. 16-22, 2009.

[104] M. Vestergaard, T. Hamada, M. Morita, and M. Takagi, "Cholesterol, lipids, amyloid beta, and Alzheimer's," Current Alzheimer Research, vol. 7, no. 3, pp. 262-270, 2010.

[105] J. E. Morley and W. A. Banks, "Lipids and cognition," Journal of Alzheimer's Disease, vol. 20, no. 3, pp. 737-747, 2010.

[106] G. P. Eckert, C. Kirsch, S. Leutz, W. G. Wood, and W. E. Muller, "Cholesterol modulates amyloid beta-peptide's membrane interactions," Pharmacopsychiatry, pp. S136-S143, 2003.

[107] G. Saxena, S. P. Singh, R. Pal, S. Singh, R. Pratap, and C. Nath, "Gugulipid, an extract of Commiphora whighitii with lipidlowering properties, has protective effects against streptozotocin-induced memory deficits in mice," Pharmacology Biochemistry \& Behavior, vol. 86, no. 4, pp. 797-805, 2007.

[108] C. Huang, J. Wang, X. Lu et al., "Z-guggulsterone negatively controls microglia-mediated neuroinflammation via blocking I $\kappa$ B- $\alpha$-NF- $\kappa$ B signals," Neuroscience Letters, vol. 619, pp. 34-42, 2016.

[109] Z. Chen, C. Huang, and W. Ding, "Z-guggulsterone improves the scopolamine-induced memory impairments through enhancement of the bdnf signal in C57BL/6J mice," Neurochemical Research, vol. 41, no. 12, pp. 3322-3332, 2016. 


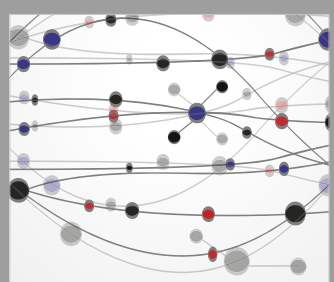

The Scientific World Journal
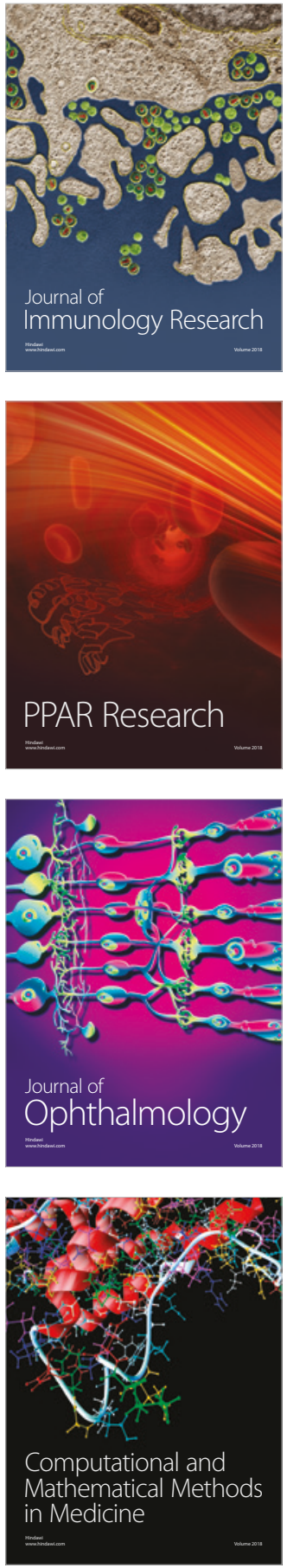

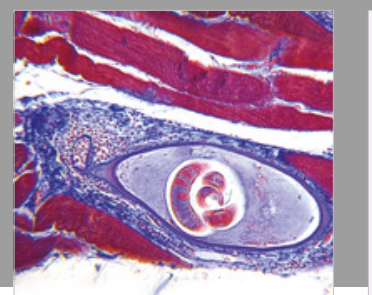

Gastroenterology Research and Practice

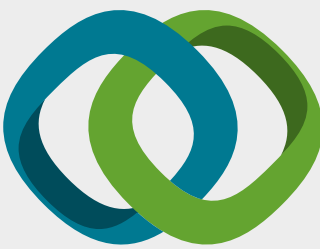

\section{Hindawi}

Submit your manuscripts at

www.hindawi.com
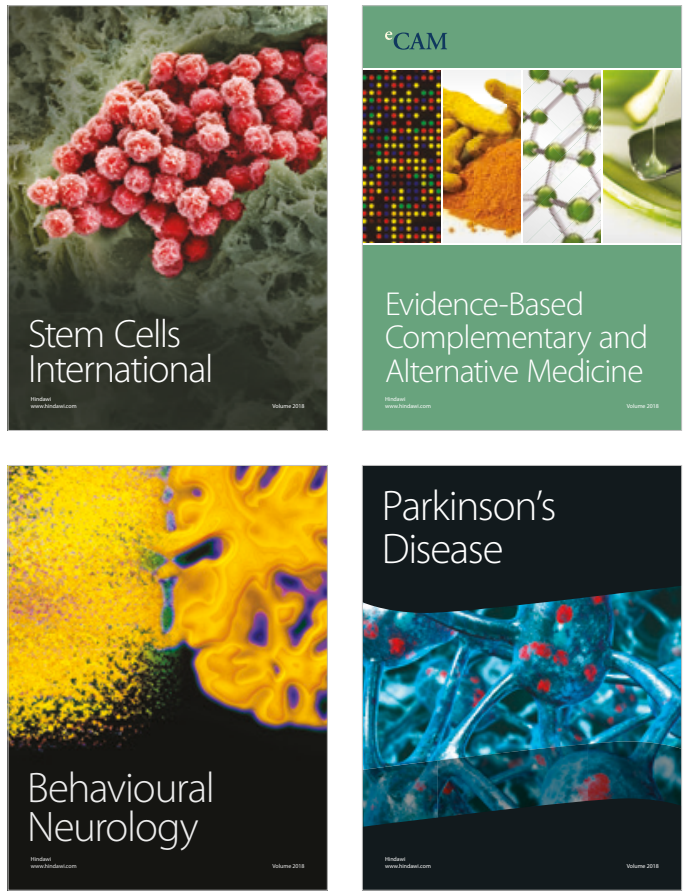

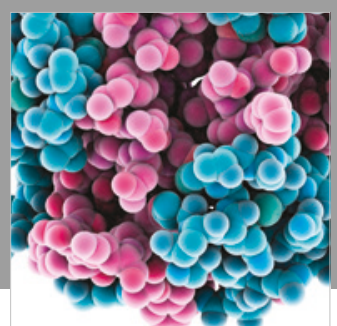

ournal of

Diabetes Research

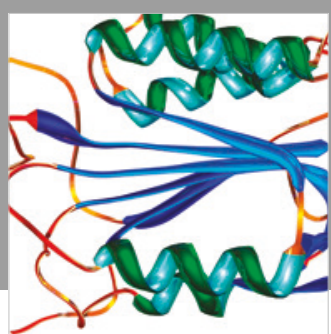

Disease Markers
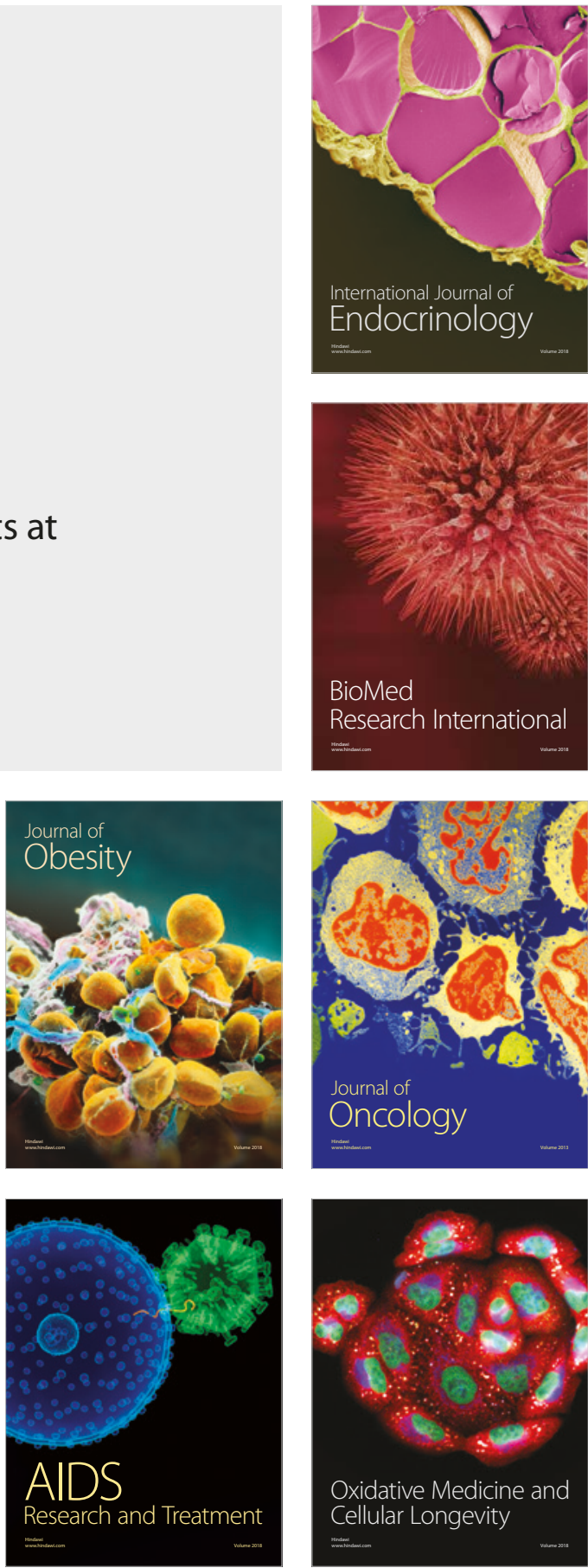